\title{
Emergency cardiac surgery and heparin resistance in a patient with essential thrombocythemia
}

\author{
Mika Nakanishi', Eri Oota, Takehiro Soeda, Kaoru Masumo, Yukihiko Tomita, Takeshi Kato and Toshihiro Imanishi
}

\begin{abstract}
A 66-year-old man with thrombocytosis was brought to our hospital to undergo removal of a left ventricular thrombus. He had developed cerebral infarction 6 days before presenting to the hospital and suffered from right incomplete hemiparalysis. Blood tests on admission revealed his platelet count to be $124.3 \times 10^{4} / \mathrm{ml}$. The urgent removal operation was performed under general anesthesia. For carrying out extracorporeal circulation (ECC), approximately three times as much heparin as expected was needed, as well as antithrombin III (AT III) administration. This met the definition of heparin resistance. The thrombus was removed and surgical left ventricular reconstruction was performed. Aspirin and warfarin were initiated on postoperative day 5 . A bone marrow biopsy was performed on postoperative day 8, which revealed hypercellular marrow with megakaryocyte proliferation, and the patient was diagnosed as having essential thrombocythemia (ET). Although hydroxycarbamide administration started on postoperative day 10 , his platelet count increased to $290.7 \times 10^{4} / \mu$ on postoperative day 13. The counts descended gradually, and on postoperative day 34 , his platelet count reached the normal range and he was discharged from the hospital. In the perioperative period, his new neurologic abnormality did not appear. Addition of heparin, administration of AT III, and coating the cardiopulmonary bypass circuit with heparin or macromolecular polymer prevented clot formation and enabled safe ECC in a patient with ET and a high platelet count.
\end{abstract}

Keywords: Essential thrombocythemia, Heparin resistance, Emergency cardiac surgery

\section{Background}

Essential thrombocythemia (ET) is classified as a myeloproliferative neoplasm. The characteristics are megakaryocyte proliferation in the bone marrow, continuously very high platelet counts $\left(>45 \times 10^{4} / \mu \mathrm{l}\right)$, and morphological abnormalities of platelets. ET is ruled out if there are morphological abnormalities of the red or white blood cells. Progression of ET causes both thrombotic and hemorrhagic diathesis. Thrombotic events occur more often than hemorrhagic events, and thrombi form more frequently in arteries than in veins. Effective treatments are anticoagulant therapy and some drugs that reduce platelet numbers, such as hydroxyurea, anagrelide, Janus kinase 2 (JAK2) inhibitors, and $\alpha$-interferon [1].

\footnotetext{
* Correspondence: mikadairisa@gmail.com

Department of Anesthesia, Osakafu Saiseikai Noe Hospital, Fruichi 1-3-25, Joto-ku, Osaka City, Osaka, Japan
}

(c) The Author(s). 2016 Open Access This article is distributed under the terms of the Creative Commons Attribution 4.0 International License (http://creativecommons.org/licenses/by/4.0/), which permits unrestricted use, distribution, and reproduction in any medium, provided you give appropriate credit to the original author(s) and the source, provide a link to the Creative Commons license, and indicate if changes were made.
There are no clear guidelines on the pre- or postoperative management of patients with ET undergoing cardiac surgery. There have been some case reports on patients with ET who underwent cardiac surgery under cardiopulmonary bypass $(\mathrm{CPB})$. In two reports, the platelet count was reduced to a normal range using hydroxyurea or $\alpha$ interferon before surgery was performed $[2,3]$. In the other reports, the platelet count was reduced by therapeutic plateletpheresis procedures preoperatively $[4,5]$. One case report on urgent cardiac surgery under CPB for a patient with ET and a high platelet count was published in Japanese [6]. We present a case report of a patient with ET and a high platelet count who underwent urgent left ventricular thrombus removal under $\mathrm{CPB}$.

\section{Case presentation}

A 66-year-old man weighing $49.9 \mathrm{~kg}$ developed cerebral infarction and right hemiparalysis. Transthoracic

\section{Springer Open}


echocardiography (TTE) showed globally decreased left ventricular function (visual ejection fraction $30 \%$ ) and a left ventricular foreign body. Infectious endocarditis was suspected because he also had a fever and elevated C-reactive protein levels and white blood cell count. Antibiotics were administered, but after 2 days the foreign body grew. His platelet count was $130.6 \times 10^{4} / \mu \mathrm{l}$, which suggested thrombocytosis and left ventricular thrombus. Administration of heparin did not improve the thrombus and 6 days after the onset of cerebral infarction the patient was urgently brought to our hospital to have the thrombus removed.

He explained that he had undergone a procedure for a gastric ulcer 1 year before, but he was not aware of his cardiac abnormality on admission. He suffered from right hemiparalysis. His platelet count was $124.3 \times 10^{4}$ / $\mu \mathrm{l}$, his white blood cell count was $156 \times 10^{2} / \mu \mathrm{l}$, and his red blood cell count was $536 \times 10^{4} / \mu \mathrm{l}$. Abnormal white blood cells were not observed. TTE showed severe hypokinesis and akinesis from the middle to the apical areas of the left ventricle. The visual ejection fraction was approximately $35 \%$. The left ventricular thrombus was located in the septal segments and was $15.5 \times 30.0 \mathrm{~mm}$ as measured by TTE.

The urgent removal operation was performed under general anesthesia as soon as hospitalization and several examinations were accomplished. General anesthesia was induced with midazolam, fentanyl, and rocuronium, and maintained with propofol, remifentanil, fentanyl, and rocuronium. Transesophageal echocardiography (TEE) showed a fragile thrombus, not in the left atrial appendage but in the left ventricle (Fig. 1). The activated coagulation time (ACT) was $182 \mathrm{~s}$, and the antithrombin III (AT III) level was $74.6 \%$. After heparin sodium $360 \mathrm{IU}$ per $\mathrm{kg}$ bodyweight $(\mathrm{IU} / \mathrm{kg})$ was administered intravenously, the ACT reached $261 \mathrm{~s}$. Heparin sodium $400 \mathrm{IU} / \mathrm{kg}$ was added and CPB was started. Despite administration of heparin, the ACT only reached $350 \mathrm{~s}$, which was not long enough to carry out extracorporeal circulation (ECC). AT III concentrate $\left(\right.$ Neuart $\left.^{\mathrm{TM}}\right) 750 \mathrm{IU}$ and heparin sodium $100 \mathrm{IU} /$ $\mathrm{kg}$ were administered and the ACT extended to $459 \mathrm{~s}$. The patient's AT III level was examined after administration of the AT III concentrate and was found to be $54.9 \%$. Further, AT III was administered (750 IU), and the AT III level reached $75.3 \%$ (Fig. 2).

The areas of the left ventricle supplied by the left anterior descending (LAD) artery were thin and a left ventricular aneurysm that contained the thrombus was observed. The thrombus was very fragile and partially liquid. The border between normal tissue and scar tissue of the left ventricle was clear, and the size of the scar was $60 \times 40 \mathrm{~mm}$. The thrombus was removed and surgical left ventricular reconstruction was performed. A CPB circuit coated by heparin or macromolecular polymer was used and no clots were seen in the circuit. An intraaortic balloon pump (IABP) was inserted and used to keep systolic blood pressure low and prevent left ventricular rupture. Protamine sulfate $90 \mathrm{mg}(1.8 \mathrm{mg} / \mathrm{kg})$ was administered intravenously to neutralize the heparin, and the ACT returned to $163 \mathrm{~s}$. The regional cerebral oxygen saturation was monitored by near infrared spectroscopy during anesthesia; no obvious changes were observed. The anesthetic duration was 6 h $29 \mathrm{~min}$, the ECC time was $2 \mathrm{~h} 44 \mathrm{~min}$, and the cross-clamp time was $1 \mathrm{~h} 59 \mathrm{~min}$. Blood loss was $1401 \mathrm{~g}$. Besides crystalloid solution, $1200 \mathrm{ml}$ of fresh frozen plasma (FFP),

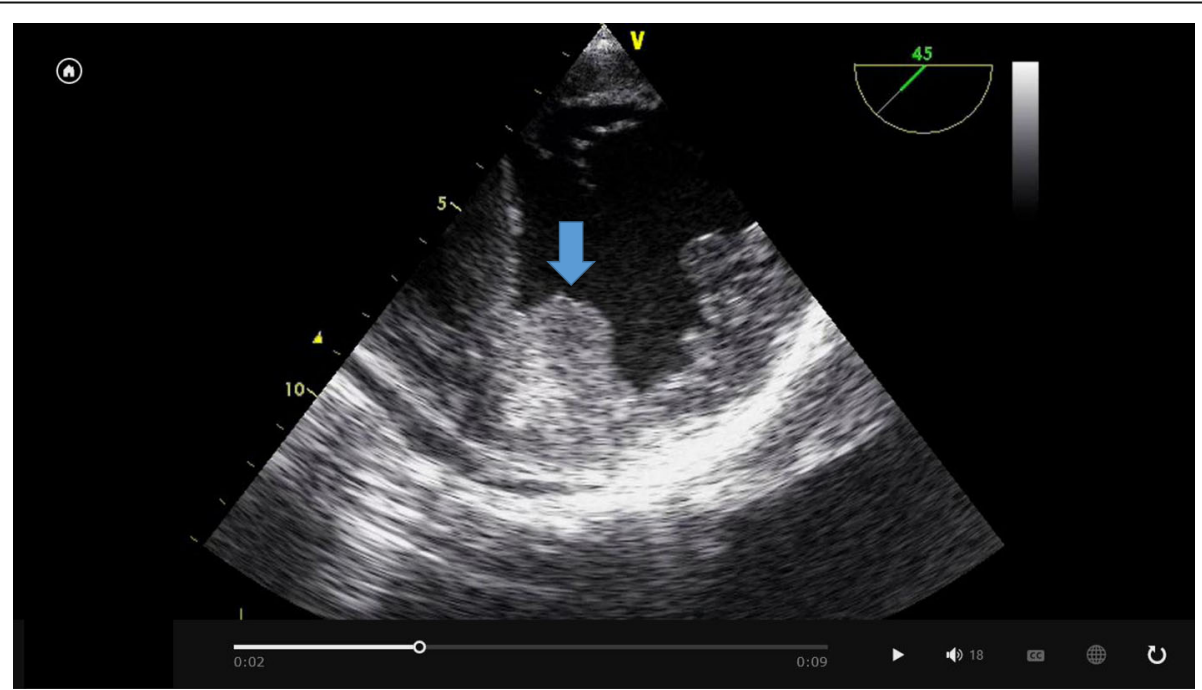

Fig. 1 Left ventricular thrombus observed by transesophageal echocardiography under general anesthesia. The thrombus ( $(\zeta)$ was mobile and was located in the septal areas 


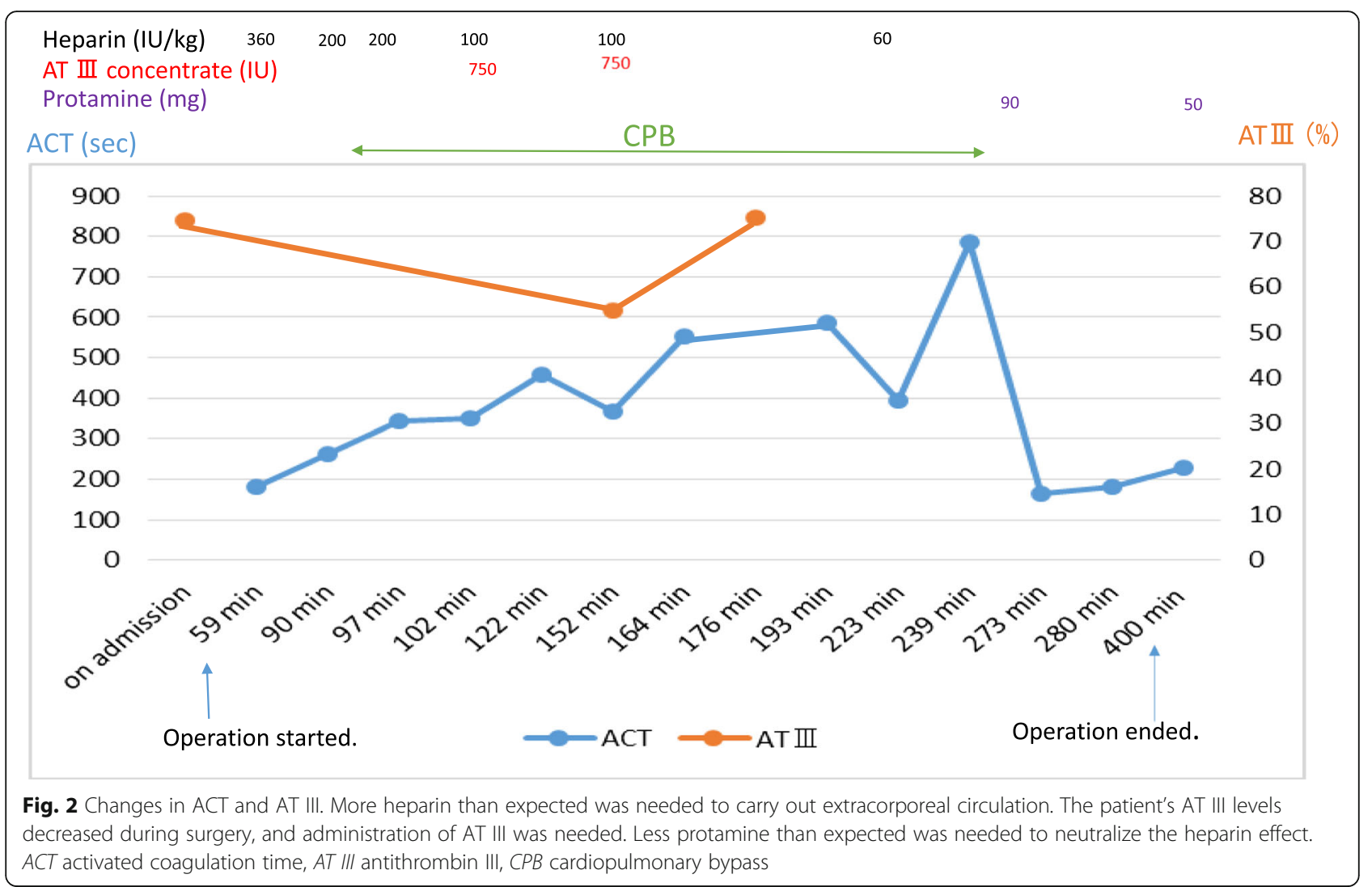

$1400 \mathrm{ml}$ of packed red blood cells, and $350 \mathrm{ml}$ of albumin were administered.

The patient entered an intensive care unit after surgery and protamine sulfate $50 \mathrm{mg}$ was administered intravenously because his ACT was still 230 s. The post-surgical platelet count was $55.9 \times 10^{4} / \mu \mathrm{l}$. Bacterial cells were not found in the removed thrombus. The IABP was removed on postoperative day 3 , and the patient was taken off mechanical ventilation support on postoperative day 6. Aspirin and warfarin were initiated on postoperative day 5. A bone marrow biopsy was performed 8 days after the surgery, which revealed hypercellular marrow with megakaryocyte proliferation. The patient was diagnosed as having ET. Although hydroxycarbamide administration started on postoperative day 10 , the patient's platelet count increased to $290.7 \times 10^{4} / \mu \mathrm{l}$ on postoperative day 13 . The count descended gradually, and on postoperative day 27 it reached $100 \times 10^{4} / \mu \mathrm{l}$. In the perioperative period, his new neurologic abnormality did not appear. On postoperative day 28, cardiac angiography revealed that segments 7 and 8 of the LAD artery had $90 \%$ stenosis. Left ventriculography showed akinesis of segments 3 and 6 but no thrombus. On postoperative day 34 , the patient's platelet count was $37.4 \times 10^{4} / \mu \mathrm{l}$ and he was discharged from the hospital.

\section{Discussion}

Patients with ET frequently develop thrombotic attacks especially in the brain, heart, and distal arteries [1]. Removal from the heart has risks, and one patient with right atrial thrombus was reported to choose anticoagulant therapy without surgical removal [7]. Our patient developed cerebral infarction, and the size of his thrombus did not reduce despite heparinization; therefore, he decided to undergo a removal operation under $\mathrm{CPB}$. His high platelet count was strongly suspected to be caused by ET before the surgery. However, there was not sufficient time to make a diagnosis or to reduce the platelet count using cytoreductive drugs because the left ventricular thrombus was mobile and the cerebral infarction may have worsened.

A 22-year-old patient with ET was reported to undergo aortic valve replacement under $\mathrm{CPB}$ after his platelet count was reduced to $30.1 \times 10^{4} / \mu$ l by treatment with $\alpha$ interferon [2]. A 64-year-old patient with ET was also reported to receive mitroaortic valve replacement under $\mathrm{CPB}$ after his platelet count was reduced to $30 \times 10^{4} / \mu \mathrm{l}$ by treatment with hydroxyurea [3]. A 54-year-old patient with ET was reported to have cardiac artery bypass surgery under $\mathrm{CPB}$ with a high platelet count: $99 \times 10^{4} / \mu \mathrm{l}[6]$. This case was urgent and there was not sufficient time to reduce the platelet count. In this case, heparin $300 \mathrm{IU} / \mathrm{kg}$ 
was not enough to increase the ACT to longer than $400 \mathrm{~s}$, and eventually $500 \mathrm{IU} / \mathrm{kg}$ heparin was needed. The ECC time was $1 \mathrm{~h} 10 \mathrm{~min}$, and heparin $200 \mathrm{IU} / \mathrm{kg}$ was added to keep the ACT longer than $400 \mathrm{~s}$ under CPB. However, $1.5 \mathrm{mg} / \mathrm{kg}$ protamine was sufficient to neutralize the heparin effect. Perioperative thrombotic events did not occur in this case.

Some abstracts reporting on CPB for patients with ET were presented at academic conferences in Japan. An 81-year-old patient with ET was reported to undergo aortic valve replacement under $\mathrm{CPB}$ with a high platelet count of $139.8 \times 10^{4} / \mu \mathrm{l}[8]$. Heparin $300 \mathrm{IU} / \mathrm{kg}$ was administered before ECC and nafamostat mesilate $30 \mathrm{mg} / \mathrm{h}$ was continuously delivered during the procedure. The CPB circuit was not coated with heparin or other anticoagulant substances. Despite delivering anticoagulant drugs, clots were observed in the reservoir and the aortic filter, which eventually needed to be changed. Another summary reported that a 57-year-old patient with ET had mitral valve plasty under $\mathrm{CPB}$ with a platelet count of $121.8 \times 10^{4} / \mu \mathrm{l}$ [9]. The dose of heparin administered was not referred to, but delivering heparin continuously into the $\mathrm{CPB}$ circuit and using a CPB circuit coated with heparin enabled safe ECC and the reservoir did not need to be changed. In another abstract, the authors reported that a 64-year-old patient who had suspected ET underwent mitral valve plasty under $\mathrm{CPB}$ with a platelet count of $73.2 \times 10^{4} / \mu \mathrm{l}[10]$. Heparin $(200 \mathrm{IU} / \mathrm{kg})$ was administered before ECC and at that point, the ACT was $236 \mathrm{~s}$. The $\mathrm{CPB}$ circuit was coated with anticoagulants, but these were not referred to in detail. During the $2 \mathrm{~h}$ $41 \mathrm{~min}$ ECC, 50,000 IU heparin was delivered. ACT was checked seven times during $\mathrm{CPB}$, but only twice was it longer than $400 \mathrm{~s}$. The reservoir did not need to be changed, although clots were observed. These case reports demonstrate heparin resistance and the hypercoagulable state and difficulties experienced with $\mathrm{CPB}$ in patients with ET.

A 73-year-old man with ET was reported to undergo cardiac surgery after his platelet count had been reduced to a normal range using three therapeutic plateletpheresis procedures [4]. Therapeutic plateletpheresis is a useful method for rapidly reducing the platelet count, but there are no clear guidelines for this procedure for ET patients. The presence of nonfunctional platelets in ET patients poses a problem in establishing a safe preoperative baseline platelet count. Furthermore, it is controversial whether this reduction is adequate for long-term maintenance because the platelet count often rebounds in ET patients [4]. In our case, plateletpheresis might have been effective, but our hospital did not have the necessary equipment.

Thrombocytosis (platelet count $>40 \times 10^{4} / \mu \mathrm{l}$ ) is known to cause heparin resistance [11], as seen in several case reports described above. Heparin resistance is usually defined as the failure to achieve an ACT of $480 \mathrm{~s}$ after $450 \mathrm{IU} / \mathrm{kg}$ of heparin [12]. Heparin resistance can be caused by mechanisms independent of AT or mechanisms related to AT deficiency. The former mechanisms are nonspecific and poorly defined. The risk factors are abnormal platelets; intravenous administration of nitroglycerin; and increased heparin-binding proteins, such as chemokines, extracellular matrix proteins, growth factors, enzymes, and miscellaneous proteins (factor VIII, von Willebrand factor, and so on). After intravenous administration, heparin can bind to several molecules and platelets that can result in reduced biologic availability. By this mechanism, thrombocytosis might cause heparin resistance. However, the extent to which each of these risk factors contributes to the phenomenon of heparin resistance in the cardiac surgical population is not clear [13]. Clinically significant heparin resistance is suspected to be caused by either AT III deficiency or type 2 heparin-induced thrombocytopenia [14]. Although in many cases heparin addition resolves heparin resistance, sometimes administration of FFP or AT III is necessary for AT III deficiency [12].

AT III is one of the main natural coagulation system inhibitors. It inhibits not only thrombin and factor Xa but also factors IXa, XIa, and XIIa, kallikrein, and plasmin. Antithrombin's activity is potentiated by heparin and may be a key component of the heparin response. AT III levels are known to decrease after recent or active thrombosis, surgical procedures, disseminated intravascular coagulation, or full-dose heparin administration. Full-dose heparin can lower AT III levels by $30 \%$ within several days, but the levels recover after discontinuing heparin [15].

In our case, AT III administration and approximately three times as much heparin as expected were needed in order to carry out ECC. Possible reasons for the decrease in AT III under CPB were because it was consumed by administration of too much heparin, the surgical procedure itself, and the patient's hypercoagulable state. Addition of heparin, administration of AT III, and coating the $\mathrm{CPB}$ circuit with heparin or macromolecular polymer prevented clot formation and enabled safe ECC. This suggested that in this case, heparin resistance was caused by mechanisms independent of AT and mechanisms related to AT deficiency.

To neutralize the heparin effect, protamine was titrated stepwise while measuring $\mathrm{ACT}$, so the dose of protamine administered in our case was low. We did not want ACT to be completely normalized because of the risk of thrombophilia.

The patient's platelet count gradually increased after the surgery due to rebound phenomena, but anticoagulant therapy with aspirin and warfarin prevented thrombotic 
events, and hydroxycarbamide reduced the platelet count to a normal range. Anagrelide would have been inappropriate because of its cardiac depression side effect, and JAK2 inhibitors could not be prescribed under health insurance in Japan. Alpha-interferon was not chosen because it is not a standard treatment for ET.

\section{Conclusions}

Addition of heparin, administration of AT III, and coating the $\mathrm{CPB}$ circuit with heparin or macromolecular polymer prevented clot formation and enabled safe ECC in a patient with ET and a high platelet count.

\section{Acknowledgements}

We would like to thank Enago (www.enago.jp) for the English language review.

We appreciate our hospital's medical engineers-Mamoru Yasumi and Kouji

Sato-for their skill of ECC and their help.

\section{Authors' contributions}

MN anesthetized and examined the patient before and after surgery and wrote this report. EO, TS, KM, YT, TK, and TI anesthetized the patient. All authors read and approved the final manuscript.

\section{Competing interests}

The authors declare that they have no competing interests.

\section{Consent for publication}

The patient's consent to publish this case report was obtained and documented.

Received: 17 August 2016 Accepted: 4 November 2016

Published online: 09 November 2016

\section{References}

1. Shimizu T, Ikeda Y. Essential thrombocythemia (in Japanese). Jpn J Med Pharm Sci. 2010;63:383-90.

2. Ahmed K, Vohra HA, Milne A, Langley SM. Aortic valve replacement in a young patient with essential thrombocytosis. J Cardiothorac Surg. 2008;3:5.

3. Gutierrez-Martin MA, Araji OA, Miranda N, Barquero JM. Mitroaortic valve replacement after aortic transapical approach failure in a patient with essential thrombocytosis. Interact Cardiovasc Thorac Surg. 2010;11(3):360-1.

4. Das SS, Bose S, Chatterjee S, Parida AK, Pradhan SK. Thrombocytapheresis: managing essential thrombocythemia in a surgical patient. Ann Thorac Surg. 2011;92(1):e5-6. doi:10.1016/j.athoracsur.2011.02.050.

5. Nurkalem Z, Uslu N, Gorgulu S, Eren M. Left main coronary thrombosis with essential thrombocythemia. J Thromb Thrombolysis. 2006;22(3):165-7.

6. Kotani N, Sakai T, Ohshima S, Kudoh A, Dobashi N, Matsuki A. Anesthetic experience of a patient with essential thrombocythemia. Masui. 1990;39: 114-7.

7. Maemura S, Yamada S, Ishizuka M, Yamamoto K, Takizawa M, Uozumi H, Ikenouchi H. Pulmonary thromboembolism complicated with right atria thrombus in the course of thrombocytosis in patient with essential thrombocythemia. ICU CCU. 2015:39:589-92.

8. Seo N, Tanaka T, Fujita Y, Tanaka K, Arata S. Extracorporeal circulation and the hypercoagulable state which obliged the reservoir to be changed in a patient with essential thrombocythemia: a case report (in Japanese). J Extra Corpor Technol. 2015:42(3):268.

9. Oka S, Matsushima N, Norisaka S, Kawakami Y, Nishimori K, Sakurai O. Extracorporeal circulation in a patient with essential thrombocythemia: a case report (in Japanese). J Extra Corpor Technol. 2014;41(3):422.

10. Morimoto S, Yamana M, Shimizu K, Narayama K, Nagashima K, Mouri N, Ogasawara A, Yamaguchi A, Yamamoto H, Oosawa H, Sakurada T, Araki E. Extracorporeal circulation in a patient suspected to have essential thrombocythemia: a case report (in Japanese). J Extra Corpor Technol. 2008; 35(3):289.
11. Gayoso JM. 5-year incidence of thrombocytosis and the effect on heparin dose response and heparin requirements. J Extra Corpor Technol. 1999; 31(4):184-90.

12. Beattie GW, Jeffrey RR. Is there evidence that fresh frozen plasma is superior to antithrombin administration to treat heparin resistance in cardiac surgery? Interact Cardiovasc Thorac Surg. 2014;18(1):117-20.

13. Finley A, Greenberg C. Review article: heparin sensitivity and resistance: management during cardiopulmonary bypass. Anesth Analg. 2013;116(6): 1210-22.

14. Guermazi S, Znazen R. Resistance to curative treatment by unfractionned heparin. Rev Med Interne. 2009:30(4):331-4.

15. Khor B, Van Cott EM. Laboratory tests for antithrombin deficiency. Am J Hematol. 2010;85(12):947-50.

\section{Submit your manuscript to a SpringerOpen ${ }^{\circ}$ journal and benefit from:}

- Convenient online submission

- Rigorous peer review

- Immediate publication on acceptance

- Open access: articles freely available online

- High visibility within the field

- Retaining the copyright to your article

Submit your next manuscript at $>$ springeropen.com 